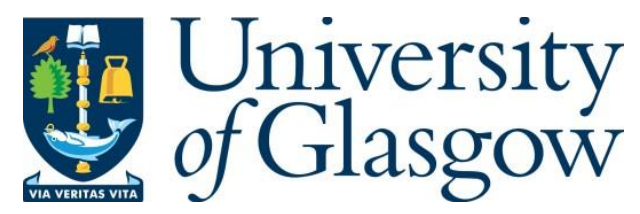

Wang, Y. et al. (2020) Covalent immobilization of biomolecules on stent materials through mussel adhesive protein coating to form biofunctional films. Materials Science and Engineering C: Biomimetic and Supramolecular Systems, 106, 110187. (doi:10.1016/j.msec.2019.110187)

There may be differences between this version and the published version. You are advised to consult the publisher's version if you wish to cite from it.

\title{
http://eprints.gla.ac.uk/195718/
}

Deposited on: 11 September 2019

Enlighten - Research publications by members of the University of Glasgow http://eprints.gla.ac.uk 


\section{Covalent immobilization of biomolecules on stent materials through mussel adhesive protein coating to \\ form biofunctional films}

Yi Wang, ${ }^{\mathrm{a}, 1}$, Hualin Lan ${ }^{\mathrm{a}, 1}$, Tieying Yin ${ }^{\mathrm{a},}$, Xiaojuan Zhang ${ }^{\mathrm{a}}$, Junyang Huang, Haiyang Fu' ${ }^{\mathrm{b}}$, Junli Huang, ${ }^{\mathrm{a}}$, Sean McGintyc, Hao Gao ${ }^{\mathrm{d}}$, Guixue Wanga, ${ }^{\mathrm{a}}$, Zhaoxu Wang ${ }^{\mathrm{b}, *}$

${ }^{a}$ Key Laboratory for Biorheological Science and Technology of Ministry of Education, State and Local Joint Engineering Laboratory for Vascular Implants, College of Bioengineering at Chongqing University, Chongqing, China

${ }^{\mathrm{b}}$ Laboratory of Biomaterials and Tissues Engineering, National Institutes for Food and Drug Control, Beijing, China

${ }^{\mathrm{c}}$ Division of Biomedical Engineering, University of Glasgow, Glasgow, UK

${ }^{\mathrm{d}}$ School of Mathematics and Statistics, University of Glasgow, Glasgow, UK

*Corresponding authors:

Prof. Guixue Wang (PhD), Bioengineering College of Chongqing University, Chongqing 400030, China; Tel: +86-23-65102508, Fax: +86-23-65102507; E-mail: wanggx@cqu.edu.cn

Prof. Zhaoxu Wang (PhD), Laboratory of Biomaterials and Tissues Engineering, National Institutes for Food and Drug Control, Beijing 100050, China ; E-mail: wangzx@nicpbp.org.cn

Assoc. Prof. Tieying Yin (PhD), Bioengineering College of Chongqing University, Chongqing 400030, China; Tel: +86-23-65102508, Fax: +86-23-65102507; E-mail: ilyyty28@126.com

${ }^{1}$ These authors contributed equally to this work.

ABSTRACT: It is widely accepted that surface biofunctional modification may be an effective approach to improve biocompatibility and confer new bioactive properties on biomaterials. In this work, mussel adhesive protein (MAP) was applied as a coating on $316 \mathrm{~L}$ stainless steel substrates (316L SS) and stents, and then either 
immobilized VEGF or CD34 antibody were added to create biofunctional films. The properties of the MAP coating were characterized by scanning electron microscope (SEM), atomic force microscope (AFM) and water contact angle test. Universal tensile testing showed that the MAP coating has adequate adhesion strength on a 316L stainless steel material surface. Subsequent cytotoxicity and hemolysis rate tests showed that the MAP coatings have good biocompatibility. Moreover, using N-(3Dimethylaminopropyl)-N`-ethylcarbodiimide hydrochloride and $\mathrm{N}$ hydroxysulfosussinimide (EDC/NHS) chemistry, VEGF and CD34 antibody were immobilized on the MAP coatings. The amount and immobilized yield of VEGF on the MAP coatings were analyzed by enzyme-linked immuno-assays (ELISA). Finally, an endothelial cells culture showed that the VEGF biofunctional film can promote the viability and proliferation of endothelial cells. An in vitro $\mathrm{CD} 34^{+}$cells capturing test also verified the bioactive properties of the CD34 antibody coated stents. These results showed that the MAP coatings allowed effective biomolecule immobilization, providing a promising platform for vascular device modification.

Keywords: Vascular stents; Mussel adhesive protein (MAP); Covalent binding; Biomolecule; Biofunctional films

\section{Introduction}

Vascular stents are the most commonly used treatment for coronary artery disease, a condition which continues to be the leading cause of death in the western world and many other developed countries [1-3]. While coronary artery stenting is now relatively mature, significant scientific and technological challenges still remain, 
particularly in relation to in-stent restenosis (ISR) and late stent thrombosis (LST) [4]. Despite intense research in the last decade, the latest generation of coronary stents have only slightly reduced revascularisation rates compared to their first generation counterparts. Revascularisation rates are still 3-5\% per annum with the latest devices [5], representing hundreds of thousands of patients worldwide. LST associated with delayed healing remains a major concern and has led to a need for prolonged treatment with expensive dual anti-platelet therapy. It is believed that ISR and LST may be tackled by accelerating the arterial healing process following stent deployment, and in particular reducing the time taken for a functional endothelium to cover the stent struts.

The vascular stents currently applied in the clinic are predominantly made of stainless steel, titanium, and cobalt-based alloys. Although these metal materials have good biomechanical performance and corrosion resistance, their biocompatibility is typically poor [6-8]. To improve biocompatibility and bioactivity, various surface modifications may be adopted to modify these materials. Current surface functionalization methods include plasma treatment, deposition of self-assembled monolayers (SAM), functionalized silanes, Langmuir-Blodgett films, layer-by-layer (LBL) assembly, and engineered peptide-binding surfaces [9-14]. Although these methods are widely established in laboratory research, they have substrate-dependent limitations in more widespread applications. In addition, vascular stents as a kind of blood-contacting artificial device need excellent hemocompatibility $[15,16]$. Hemocompatibility frequently is seen as the most critical aspect of biocompatibility, 
as adverse effects are not restricted locally but affect remote and vital organs. So, it is important to modify biomaterilas used as vascular stents with good hemocompatibility. However, the hemocompatibility of these conventional surface functionalization is still far from the ideal [17]. Therefore, there is a growing need to develop new coating technologies which can customized to different biomaterials and possessed good hemocompatibility.

Mussel adhesive protein (MAP) is extracted from marine mussels (Mytilus edulis), their adhesive potential have been extensively studied by researchers $[18,19]$. Mussels are promiscuous fouling organisms and have been shown to attach to virtually all types of inorganic and organic surfaces, including classically adhesionresistant materials such as poly (tetrafluoroethylene) (PTFE). Up until now, MAP has been studied extensively in the literature. Clues to MAP's adhesive versatility may lie in the amino acid composition of proteins, which are rich in 3, 4-dihydroxy-Lphenylalanine (DOPA) (content at $10-30 \mathrm{moL} \%$ ) which is a catabolic amino acid that is produced by post-translational modification of tyrosine [20-22]. Previous studies of MAPs have proposed that the adhesion depends on DOPA [23] which may form strong covalent and noncovalent interactions with substrates [24], and the higher the DOPA content, the stronger the adhesion [25]. However, the adhesion mechanism of MAPs remains unresolved. Currently, at least 12 proteins have been characterized from the byssus of Mytilus species [26]. Among them, Mytilus edulis foot protein-1 (Mefp-1), the primary cuticular protein, was the first byssal protein to be isolated from M. edulis, which has undergone much scrutiny. Mefp-1 has up to $15 \mathrm{~mol} \%$ 
DOPA and a mass of $108 \mathrm{kDa}[18]$.

Due to MAP's high-binding capacity, MAP and recombinant MAP have wide application in the fields of surface chemistry, biomedical science and ocean engineering, to name but a few [27-31]. Moreover, a few investigators have also studied the biocompatibility of MAPs and have reported that they elicit minimal immune response and cytotoxicity [32-34]. The properties of MAPs make them a promising candidate as a surface coating to modify stent materials. However, to the best of our knowledge there are no studies which consider the application of MAP to stent materials. Conferring bioactive properties to biomaterials via biomacromolecules such as growth factors or antibodies is a promising way to create new biofunction on implants [35]. Vascular endothelial growth factor (VEGF) is a potent inducer of endothelial cell (EC) proliferation, migration and tube formation, and is a key mediator in the process of angiogenesis [36-38]. There has been tremendous success in using biomaterials for immobilizing VEGF to induce neovascularization, as well as to support cell survival and differentiation [39-42]. CD34 is the main surface marker for endothelial progenitor cells EPCs [43]. Fixing CD34 antibody on the stent surface represented the earliest method to fabricate capture stents [44-46]. So far, the medical device company Orbus Neich has developed three Genous series products in which CD34 antibodies were used as capture molecules. These stents usually utilize the polymer as a coating, however the adhesion strength between the polymer and the stents material is not strong enough.

The objective of this study was to explore a new coating approach on stent 
materials using MAP and to subsequently immobilize biomacromolecules on this coating to create bioactive films. VEGF and CD34 antibody were chosen as representative biomolecules and immobilized onto a MAP coated surface (Figure 1). The properties of the MAP coating are then characterized. The amount and immobilized yield of VEGF bound to MAP coating were determined. Finally, to provide evidence for its retained biological activity after immobilization, VEGF functionalized substrates were evaluated in a culture of endothelial cells and the capture ability of CD34 antibody coated stents were tested through capturing CD34 cells in vitro.
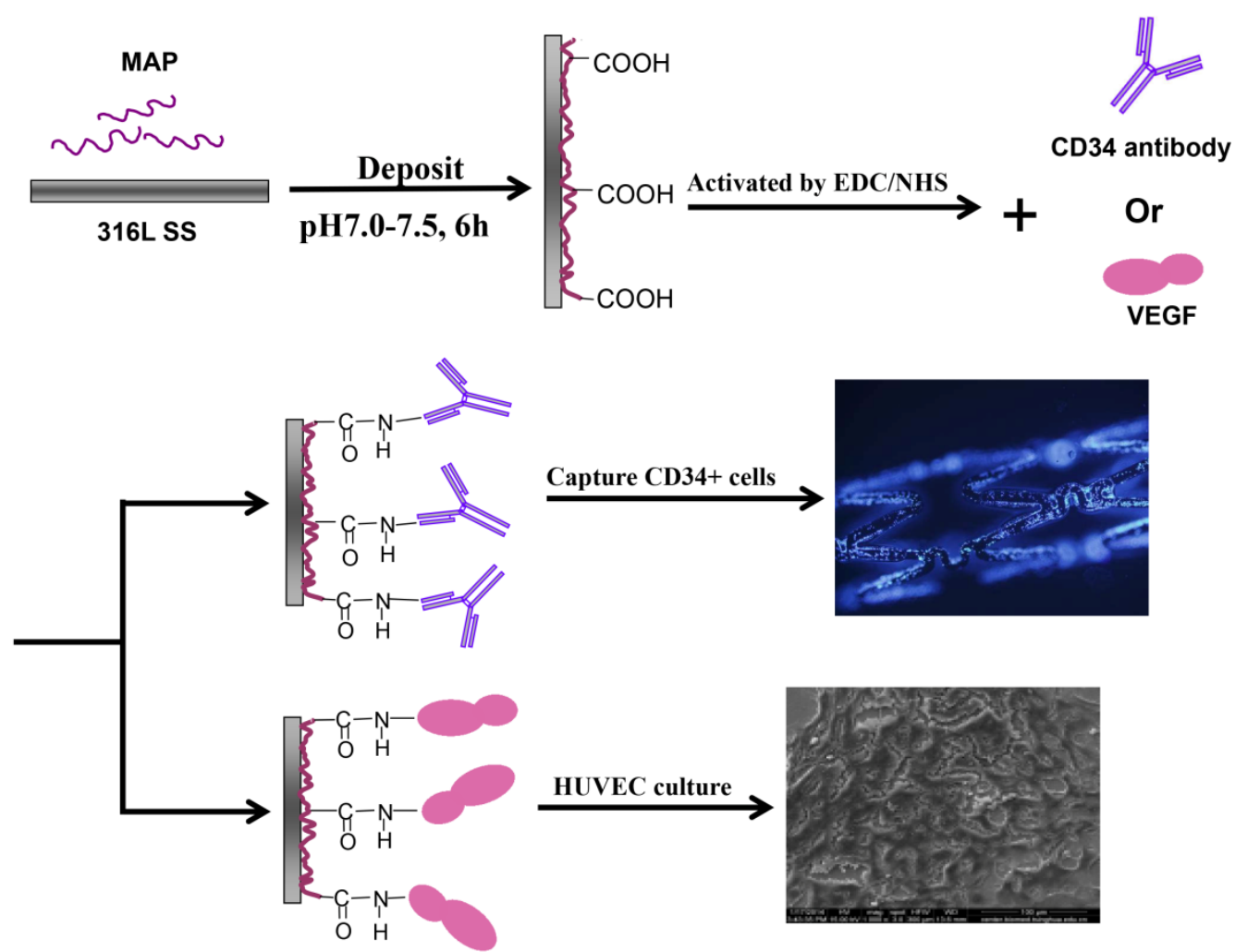

Figure 1. Surface modification with MAP coating and further biofunctionalization by immobilizing VEGF or CD34 antibody through EDC/NHS chemistry.

\section{Materials and methods}

\subsection{Materials}


MAP was obtained from Jiangyin USUN Biochemical Technology, Co. Ltd (Jiangyin, China), the main component of MAP is Mefp-1. 316 L stainless steel stents were obtained from BEIJING AMSION Co. Ltd. (Beijing, China). 316L stainless steel substrates (diameter $=15 \mathrm{~mm}$ ) were purchased from Western Metal Materials Co. Ltd (Shanghai, China). VEGF, Phycoerythrin (PE) labeled anti-human CD34 and anti-human CD34 was purchased from BioLegend (San Diego, USA). Glutaraldehyde solution ( $25 \%$ in water) was purchased from Solarbio (Beijing, China). Sulfo-NHS (N-hydroxysulfosussinimide) was purchased from Thermo Scientific (Waltham, USA). EDC (N-(3-Dimethylaminopropyl)-N`-ethylcarbodiimide hydrochloride) was purchased from Sigma-Aldrich (Billerica, USA). The sources of the various reagents used for the evaluation of hemocompatibility and cytocompatibility are mentioned in the description of experiments below. Other reagents were local products of analytical grade.

\subsection{Preparation of MAP coating on $316 L$ stainless steel substrates}

MAP solution was prepared by diluting stock solution $(10 \mathrm{mg} / \mathrm{ml})$ to $2 \mathrm{mg} / \mathrm{ml}$ with $1 \%(\mathrm{v} / \mathrm{v})$ acetic acid buffer and to promote the adhesion of the MAP on the substrates the $\mathrm{pH}$ of the MAP solution was adjusted to $7.0 \sim 7.5$ before use. Mirror polished 316L SS disks ( $\varnothing=10 \mathrm{~mm}$ ) were directly immersed in MAP solution (This MAP coating was denominated as MC) or immersed after adding $25 \%$ Glutaraldehyde $(2 \mu \mathrm{L} / \mathrm{mL}$ ) which can enhance the crosslinking of the MAP (This MAP crosslinked coating was denominated as MCC) for 6 hours at room temperature. After that, the MAP deposited films were cleaned with distilled water under ultrasound ( $10 \min \times 3$ times), then were nitrogen-dried.

\subsection{Immobilization of VEGF on MAP coated substrates}

The MAP coated substrates were activated with EDC/NHS (N-ethyl-N-(3dimethylaminopropyl) carbodiimide, N-hydroxysuccinimide) for $30 \mathrm{~min}$ at room temperature. $4 \mathrm{mg} / \mathrm{mL}$ EDC and $2.4 \mathrm{mg} / \mathrm{mL}$ NHS were used. Following activation, the samples were transferred to $0.5 \mathrm{mg} / \mathrm{mL}$ or $1 \mathrm{mg} / \mathrm{ml}$ VEGF in phosphate buffered saline (PBS; pH 7.6) at $25^{\circ} \mathrm{C}$ and kept in the dark for $3 \mathrm{~h}$. Then the obtained surfaces were washed 3 times in PBS to remove excess reagents and non-covalently bound 
VEGF. Using EDC/NHS chemistry to covalently immobilize VEGF on MC and MCC were denominated as MC/EDC/VEGF and MCC/EDC/VGEF, and without EDC/NHS chemistry to immobilize VEGF on MC and MCC were denominated as MC/VEGF and MCC/VGEF. Prior to cell seeding, VEGF-functionalized substrates were stored in PBS at $4^{\circ} \mathrm{C}$

\subsection{Preparation of CD34 antibody coated stents}

MAP coating $316 \mathrm{~L}$ stainless steel bare metal stents $(B M S)(1.8 \mathrm{~mm} \times 17 \mathrm{~mm}$, diameter $\times$ length, China) were prepared as previous processing in section 2.2. The MAP coated stents were activated with EDC/NHS for 30min at room temperature. 4 $\mathrm{mg} / \mathrm{mL}$ EDC and $2.4 \mathrm{mg} / \mathrm{mL}$ NHS were used. Following activation, the samples were transferred to $200 \mu \mathrm{g} / \mathrm{mL}$ phycoerythrin labeled CD34 antibody (PE-anti-CD34) or $\mathrm{CD} 34$ antibody in phosphate buffered saline (PBS, $\mathrm{pH} 7.6$ ) at $25^{\circ} \mathrm{C}$ and kept in the dark for 3h. PE anti-human CD34 antibody functionalized films were continuously washed with PBS several times and then for visualization under fluorescence microscopy to evaluate the presence of bound antibodies. To test the stable bond of antibody, the PE anti-human CD34 antibody functionalized stents were continuously washed with PBS under mechanical shaking for $24 \mathrm{~h}$, and then visualized under fluorescence microscopy. Prior to the cell capture test, CD34 stents were stored in PBS at $4^{\circ} \mathrm{C}$

\subsection{Characterization of MAP coating properties}

Morphology and surface roughness of the prepared MAP coating were visualized using scanning electron microscopy (SEM, Vega II-LMH, Germany) and atomic force microscopy (AFM, N8 NEOS, Bruker Nano-GmbH, Bremen, Germany). Roughness measurements are further performed on 3 images of scan size of $(15 \times 15) \mu \mathrm{m}^{2}$ from different area of the same sample to ensure homogeneity. Surface wettability was examined by observing the water contact angle on the coatings (Pheonix 300, Surface Electro Optics, Suwon, Korea). All samples were kept flat, $10 \mu \mathrm{L}$ of water was dropped on the films, and the images of the droplet on the films were captured $5 \mathrm{~s}$ after dropping. The water contact angle was measured using Image-Pro Plus (Media Cybernetics, Bethesda, MD). 


\subsection{Adhesion strength}

The adhesion strength of the coating layer was measured by tensile test methods. Firstly, MAP solution $(2 \mathrm{mg} / \mathrm{ml}$, with or without glutaraldehyde) was dropped on a 316L stainless steel substrate and then another substrate put on the MAP coated substrate. After the MAP between the substrates was dry, the two stainless steel substrate were fixed by fixture. Tensile testing was performed using a tensile testing machine (TInius Dlsen H5K-S) with a $25 \mathrm{~N}$ load mechanical sensor at a constant speed of $1.0 \mathrm{~mm} / \mathrm{min}$ and record the maximum peak. The adhesion strength was tested using both vertical and shear direction loading.

\subsection{Balloon expansion and stability tests}

The surface morphology of the BMS coated with MAP was examined by scanning electron microscopy (SEM, Vega II-LMH, Germany) before balloon expansion. A $1.8 \mathrm{~mm} \times 17 \mathrm{~mm}$ BMS coated with $\mathrm{MC}$ and $\mathrm{MCC}$ was mounted onto an angioplasty balloon and the balloon was dilated from $1.8 \mathrm{~mm}$ to $3.0 \mathrm{~mm}$ (diameter) at a pressure of $8 \mathrm{~atm}$. The post-expansion stents were examined by SEM.

\subsection{Hemolysis rate}

In order to test hemolysis rate of the samples, rabbit blood samples were obtained. $4 \mathrm{~mL}$ blood was diluted by $5 \mathrm{~mL}$ of $0.9 \%(\mathrm{w} / \mathrm{v})$ sodium chloride solution. Every test sample (diameter $10 \mathrm{~mm}$ ) was extracted in $10 \mathrm{~mL} 0.9 \%(\mathrm{w} / \mathrm{v})$ sodium chloride solution for $30 \mathrm{~min}$ at $37^{\circ} \mathrm{C}$. Untreated $0.9 \%(\mathrm{w} / \mathrm{v})$ sodium chloride solution and double distilled water served as negative and positive controls ( $\mathrm{n}=3$ each). Afterwards, $0.2 \mathrm{~mL}$ of the diluted whole blood was added and the specimens were continuously incubated at $37^{\circ} \mathrm{C}$ for $1 \mathrm{~h}$. Subsequently, the solutions were centrifuged for $5 \mathrm{~min}$ at $3000 \mathrm{rpm}$. The absorbance of supernatant was measured at $540 \mathrm{~nm}$ using a microplate reader ( $\mu$ Quant, Bio-tek instruments Inc., Winooski, USA) to determine the released hemoglobin of lysed red blood cells. The hemolysis rate is calculated as follows:

$$
\mathrm{R}=(\mathrm{A}-\mathrm{C} 1) /(\mathrm{C} 2-\mathrm{C} 1) \times 100 \%,
$$

$\mathrm{R}$ : hemolysis ratio (\%), A: absorbance of the sample (optical density (OD)), C1: 
absorbance of the negative controls (OD), C2: absorbance of the positive control (OD).

\subsection{In vitro cell cytotoxicity assay of MAP coating}

Cell cytotoxicity assay was assessed with an MTT assay. $100 \mu \mathrm{L}$ ECs were seeded at different samples in the $96-w e l l$ plate at a density of $1 \times 10^{5} / \mathrm{mL}$ and maintained in a humidified $37^{\circ} \mathrm{C} \mathrm{5 \%} \mathrm{CO} 2$ incubator for 24 hours. Then, $20 \mu \mathrm{L}$ of 3-(4, 5dimethylthiazol-2yl)-2, 5-diphenyltetrazo-lium bromide (MTT, $5 \mathrm{mg} / \mathrm{mL}$ ) was added into each well and incubated for $4 \mathrm{~h}$ at $37^{\circ} \mathrm{C}$. Finally, $150 \mu \mathrm{L}$ of dimethyl sulfoxide (DMSO) was added to the 96-well plate. The absorbance was measured at $570 \mathrm{~nm}$ and $630 \mathrm{~nm}$ using an enzyme micro-plate reader (Thermo1500, USA). All experiments were performed in triplicate.

\subsection{Detection and quantification of immobilized VEGF}

Immobilized VEGF was indirectly quantified by subtracting the amount of free, non-immobilized VEGF in the solution after the reaction and the washing solutions from the amount of free VEGF in the initial solution [47, 48]. After $3 \mathrm{~h}$ of incubation, the supernatant of the immobilization solution was collected, and the substrates were washed 3 times in $0.5 \mathrm{~mL}$ PBS. The PBS was collected and mixed with the washing solutions. The quantity of VEGF in the mixing solutions was analyzed by an enzyme linked immuno-assay (human VEGF ELISA kit, RayBiotech, Norcross, USA) according to manufacturer's instructions. Briefly, mixing solutions were added to the 96 well plates and incubated for $2.5 \mathrm{~h}$, followed by incubation with a biotinylated anti-hVEGF antibody. Subsequently, a horse radish peroxidase (HRP)-conjugated streptavidin solution was applied followed by a 3, 3', 5, 5'-tetramethylbenzidine (TMB) one-step solution. The latter one was enzymatically converted to a blue chromophore. VEGF concentration was assessed spectrophotometrically at $450 \mathrm{~nm}$ absorbance and quantified by means of a standard calibration curve. Amounts of immobilized VEGF are expressed as ng per substrate. The amount of immobilized VEGF (immVEGF), relative to the amount of free VEGF in the solution (initial VEGF) was quantified as immobilization yield, where 
(1) Immobilization yield (\%) $=\frac{\text { imm } V E G F}{\text { initialVEGF }} \times 100 \%$

(2) $[$ imm.VEGF $]=[$ initial VEGF $]-[$ non-reacted VEGF $]$.

\subsection{HUVECs and KG-1a cells culture}

Human Umbilical Vein ECs (HUVECs) (a generous gift from Dr. Lushan Liu, Nan Hua University, China) in endothelial basal media RPMI 1640 (HyClone USA, Logan, UT) supplemented with $10 \%$ fetal bovine serum (FCS; Cambrex Corp, Charles City, IA) and antibiotic/antimycotics solution (Gibco Industries Inc., Langley, OK) were grown to confluence in T-75 polystyrene flasks (Becton Dickinson and Co., Franklin Lakes, NJ). Cells were cultured in a $\mathrm{CO} 2$ incubator $(5 \% \mathrm{CO} 2)$ at $37^{\circ} \mathrm{C}$.

KG-1a cells were purchased from ATCC (ATCC CCL-246.1TM) and cultured with Iscove's Modified Dulbecco's medium supplemented with $20 \%$ fetal bovine serum. The cells were incubated at $37^{\circ} \mathrm{C}$ in a humidified atmosphere of $5 \% \mathrm{CO} 2$ with the growth medium changed every 2-3 days.

\subsection{Endothelial cell adhesion and proliferation}

ECs $\left(5 \times 10^{4}\right.$ cells per well) were seeded on different samples. After incubating for $30 \mathrm{~min}$ at $37^{\circ} \mathrm{C}$, the non-adherent cells were gently washed with phosphatebuffered saline (PBS). The cells were then fixed with 2.5\% paraformaldehyde for 30 min and incubated with $0.1 \%(\mathrm{v} / \mathrm{v})$ Triton $\mathrm{X}-100$ for $10 \mathrm{~min}$ at $37^{\circ} \mathrm{C}$. Then, the cells were stained with FITC-phalloidin for $40 \mathrm{~min}$ and the nuclei were counterstained with DAPI for $10 \mathrm{~min}$ at room temperature. Images of three random fields were obtained under a confocal laser scanning microscope (SP8, Leica). The number of adherent cells was determined using Image J software.

ECs proliferation were observed by seeding ECs on different samples at a density of $3 \times 10^{4}$ cells $/ \mathrm{cm}^{2}$. After incubation for 1, 3 and 5 days, respectively, the cells were fixed with $2.5 \%$ paraformaldehyde for $1 \mathrm{~h}$, and then were washed with PBS three times for $3 \mathrm{~min}$. Afterwards, samples were ethanol dehydrated (ascending series of ethanol) and gold sputtered $(10 \mathrm{~nm})$. Finally, the morphology of the adherent ECs was examined by SEM. 


\subsection{In vitro capture of $\mathrm{CD} 34^{+}$cells}

For capture tests, the CD34 antibody coated stents were incubated with $1 \times 10^{6} / \mathrm{mL}$ of KG-1a cells in IMDM culture media for $2 \mathrm{~h}$ at $37^{\circ} \mathrm{C}$ with a shaking rate of $150 \mathrm{rpm}$. Captured cells on the specimens were fixed with 4\% paraformaldehyde (PFA; SigmaAldrich, USA) in PBS for $20 \mathrm{~min}$ at room temperature. The cells were then permeabilized using $0.5 \%$ Triton X-100 in PBS for 3min. Subsequently, the cells stained with DAPI. After rinses with PBS, the stents were observed under a fluorescence microscope (OLYMPUS BX41, Japan), and the absorbance was measured at $570 \mathrm{~nm}$ and $630 \mathrm{~nm}$ using Gemini XPS Fluorescence Microplate Reader (Molecular Devices, USA).

\subsection{Statistical analysis}

The data obtained in this study are reported as the mean \pm standard deviation. Data obtained in different treatment groups were statistically analyzed using statistical software GraphPad Prism Version 6.0 software (GraphPad, USA). To reveal differences among the groups, one-way ANOVA followed by Tukey's test was used. The differences were considered significant at $* \mathrm{p}<0.05$.

\section{Results}

\subsection{Surface morphology and hydrophilicity of the MAP coating}

The surface morphology and roughness were observed with SEM and AFM after modification. The SEM images (Fig. 2A) and AFM images (Fig. 2B) revealed the difference in the surface morphology between 316L SS, MC, and MCC. 316L SS showed a rough surface in which a nanoscale metal texture was randomly generated, possibly due to mirror polished treatment. MAP coating for $6 \mathrm{~h}$ dramatically changed the surface morphology of $316 \mathrm{~L}$ SS, and the nanoscale metal texture almost disappeared both in MC and MCC. The MCC was flatter than MC. The average roughness (Ra) of 316L SS, MC and MCC were $7.46 \pm 1.6 \mathrm{~nm}, 9.93 \pm 2.5 \mathrm{~nm}$ and $5.93 \pm 2.2 \mathrm{~nm}$, respectively. The MCC surface was observed to be relatively 
homogeneous compared with 316L SS and MC, whereas MC had the highest Ra. The MC and MCC coated 316L SS both showed increased water contact angle (WCA) as compared to the control 316L SS (Fig. 2C). Compared with 316L SS $\left(49.40 \pm 2.21^{\circ}\right)$, the water contacts angles increased to $63.40 \pm 2.21^{\circ}(\mathrm{MC})$ and $66.3 \pm 3.54^{\circ}$ (MCC).
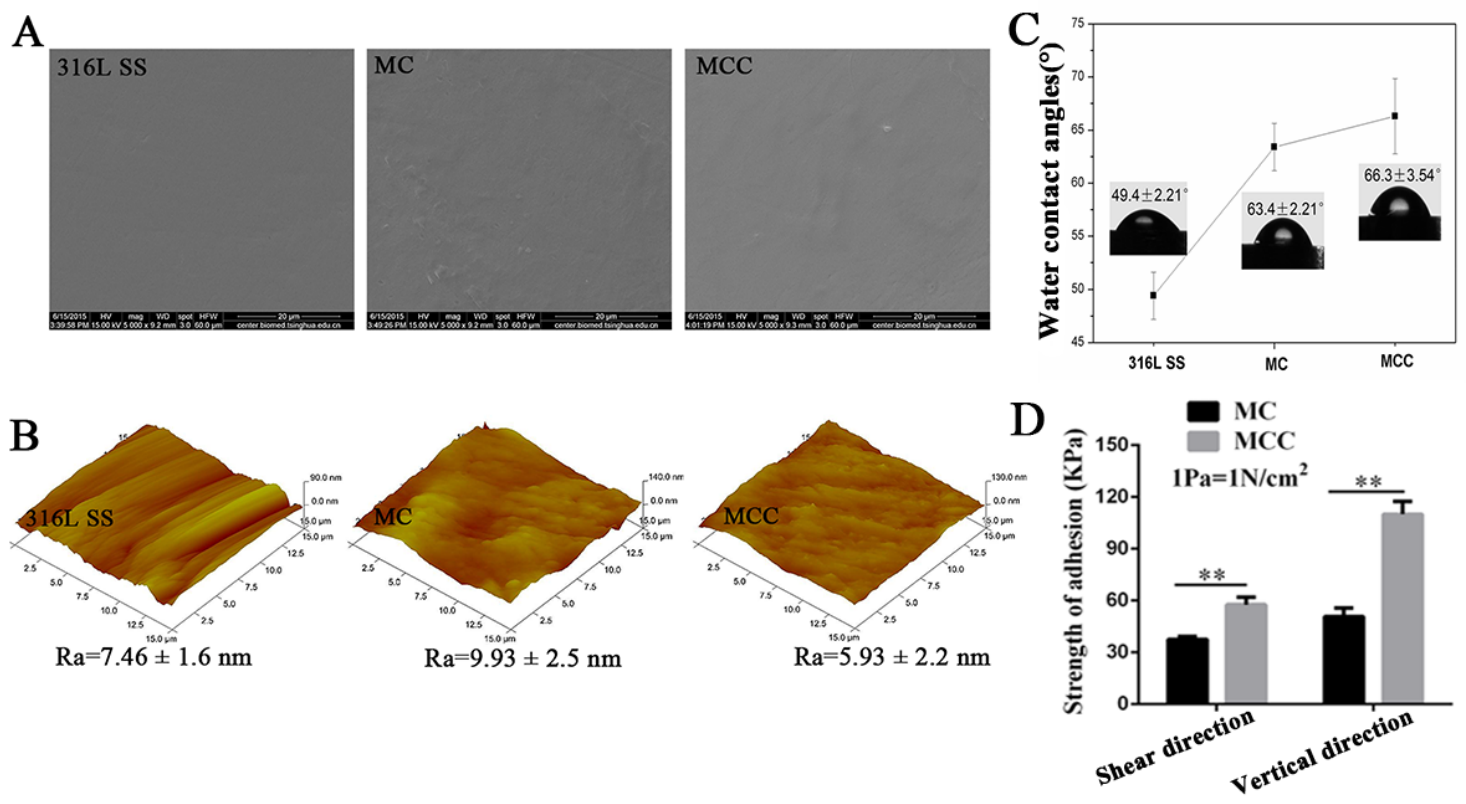

Figure 2. The characterization of MC and MCC. (A) The SEM images of 316L SS, MC and MCC. (B) The AFM images of 316L SS, MC and MCC. (C) The water contacts angles of 316L SS, MC and MCC. (D) The adhesion strength of MC and MCC on 316L SS using both shear and vertical direction loading. The values and error bars represent the means of at least three samples and standard deviations with statistical significance $(* * \mathrm{p}<0.01)$.

\subsection{Adhesion strength}

The adhesion strength of the MC and MCC coating on 316L SS were shown in Fig. 2D. No matter using shear or vertical direction loading, the adhesion strength of MCC on 316L SS was significantly higher than MC. This likely attributed to the glutaraldehyde which enhanced the bound between MAP and 316L stainless steel substrates through a cross-linking reaction. In addition, for the same coating, the adhesion strength of shear direction was lower than vertical direction.

\subsection{Balloon expansion and stability tests}

Stents undergo rigorous and complex distortion when mounted onto an angioplasty balloon and dilated. Here stent analysis was performed as an example to observe the mechanical behavior of the MAP as a coating (Fig. 3) when the stents 
were dilated to $3 \mathrm{~mm}$ at a pressure of $8 \mathrm{~atm}$. It can be clearly seen from SEM images that the MC and MCC coating deposited on a stent was very homogeneous, continuous and smooth (Fig. 3A and 3B). Figure 3A and 3B showed the SEM micrographs of the expanded stent. After dilation, the MC and MCC coating both could keep intact without delamination or destruction. This revealed that the MC and MCC coating were sufficiently flexible to follow the deformation of the $316 \mathrm{~L}$ SS that allows balloon expansion of the stent without cracking or peeling from the struts.
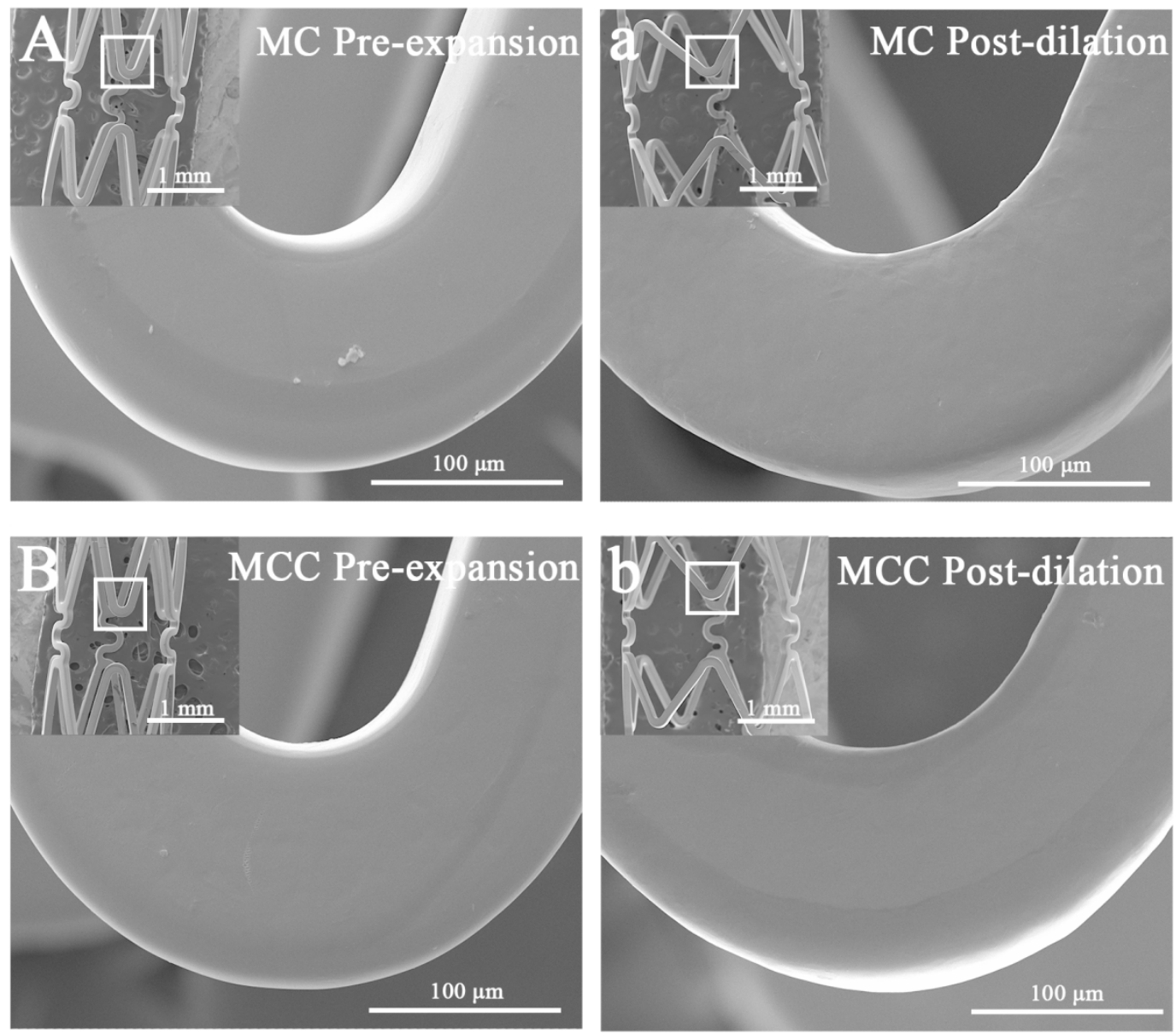

Figure 3. SEM micrographs of the 316L SS stents coated with MC or MCC at pre-expansion and post-dilation.

\subsection{Hemolysis Rate and Cell Cytotoxicity}

Typically, blood is the first body fluid which comes into contact with an implanted foreign material. It is therefore important to demonstrate that for a blood contacting material, hemolysis does not occur. A hemolysis test is therefore important when investigating implanted medical instruments. The absorbance of MC and MCC was 
shown in Figure 4A. The MC and MCC have the similar absorbance to negative control. As shown in Table 1, the hemolysis ratio of MC and MCC were well within $1 \%$, and far below the accepted threshold value of $5 \%$ [49]. It is preliminarily indicated, therefore, that the $\mathrm{MC}$ and $\mathrm{MCC}$, as a novel material, shows a sufficient level of hemocompatibility. The in vitro cell cytotoxicity test showed that the relative growth rate (RGR) of MC and MCC both exceed $99 \%$ (Figure 4 B). This demonstrated that these MAP coatings have good cytocompatibility.

A

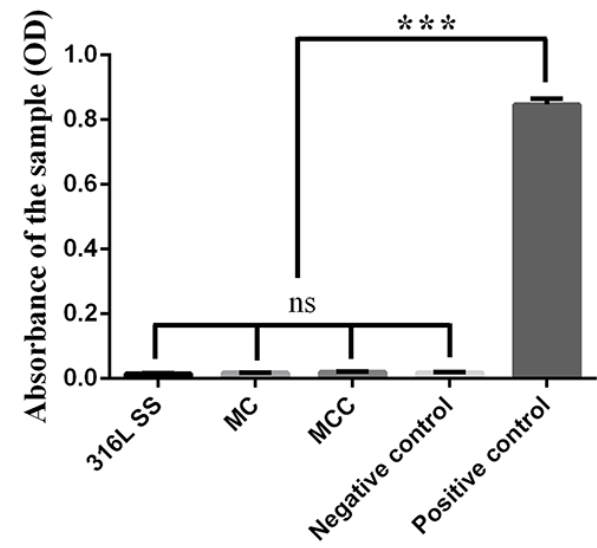

$\mathrm{C}$

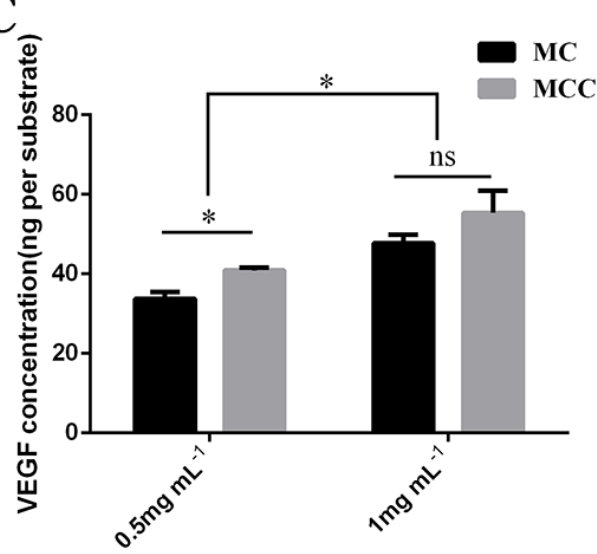

B

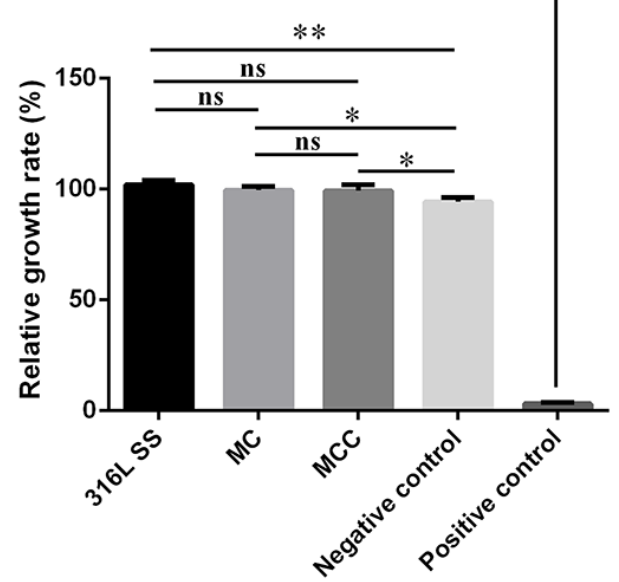

D

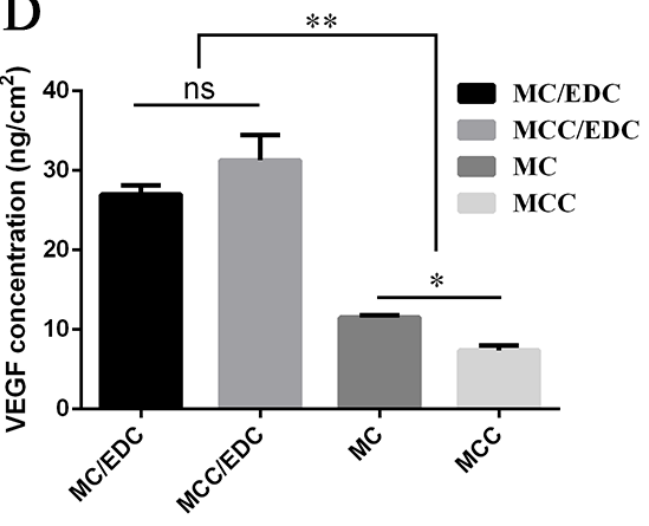

Figure 4. (A) The absorbance of 316 LSS, MC and MCC. (B) The relative growth rate (RGR) of cells cultured on 316 LSS, MC and MCC. (C) ELISA quantification of immobilized VEGF on $\mathrm{MC}$ and $\mathrm{MCC}$ through EDC/NHS chemistry at different initial VEGF concentrations. (D) The final VEGF concentrations on MC and MCC with or without EDC/NHS at the same initial VEGF concentration. The values and error bars represent the means of at least three samples and standard deviations with statistical significance $\left({ }^{*} \mathrm{p}<0.05, * * \mathrm{p}<0.01\right.$ and $\left.{ }^{* * *} \mathrm{p}<0.001\right)$. ns, no significance. 
Table 1. Hemolysis ratio of the 316L SS and MAP film (sample size: $\Phi 15 \mathrm{~mm}, \mathrm{n}=3$ )

\begin{tabular}{|c|c|c|c|c|c|}
\hline \multirow{2}{*}{ Samples } & \multicolumn{3}{|c|}{ Absorbance of the sample (A) } & \multirow{2}{*}{ Average } & \multirow{2}{*}{$\begin{array}{l}\text { Hemolysis } \\
\text { Rate }(\%)\end{array}$} \\
\hline & 1 & 2 & 3 & & \\
\hline 316L SS & 0.017 & 0.014 & 0.016 & 0.016 & -0.362 \\
\hline $\mathrm{MC}$ & 0.019 & 0.017 & 0.018 & 0.018 & -0.080 \\
\hline $\mathrm{MCC}$ & 0.021 & 0.021 & 0.019 & 0.020 & 0.161 \\
\hline Negative control & 0.019 & 0.018 & 0.019 & 0.019 & \\
\hline Positive control & 0.826 & 0.854 & 0.861 & 0.847 & \\
\hline
\end{tabular}

\subsection{Quantification of immobilized VEGF}

Amounts of immobilized VEGF were presented as ng per substrate (each substrate has a diameter of $1.5 \mathrm{~cm}$ and surface area of $1.77 \mathrm{~cm}^{2}$ ). As a first step, the effect of initial VEGF concentration on the final amount of immobilized VEGF was evaluated. Therefore, functionalization reactions were accomplished with 0.5 or $1 \mathrm{mg} / \mathrm{mL}$ VEGF while keeping all other concentrations constant. Reactions were executed on MC or MCC. An initial VEGF concentration of $1 \mathrm{mg} \mathrm{mL}^{-1}$ resulted in a significant increase in VEGF concentration on both MC and MCC coated substrates as compared to the lower initial concentrations of $0.5 \mathrm{mg} \mathrm{mL}^{-1}$ (Fig. 4 C). At the same initial VEGF concentration $(1 \mathrm{mg} / \mathrm{ml})$, the amount of VEGF bound on MCC were higher than MC, but there was no significant difference between MCC and MC (Fig. 4 C). We also found that without EDC/NHS chemistry VEGF also can immobilize on MC and MCC, and the amount of VEGF on MC were significantly higher than MCC (Fig. 4 D).

With EDC/NHS chemistry, the immobilization yields (calculated as the amount of immobilized VEGF relative to the amount of initial VEGF) were $(6.76 \pm 0.34 \%$, or $4.78 \pm 0.2 \%)$ on $\mathrm{MC}$ and $(8.18 \pm 0.154 \%$ or $5.54 \pm 0.56 \%)$ on $\mathrm{MCC}$ at concentrations of 0.5 or $1 \mathrm{mg} / \mathrm{mL}$ VEGF, respectively (Table 2 ). In agreement, the immobilization 
yields on MCC were higher than MC. Previously, the conjugation yield of VEGF on the collagen scaffolds via EDC/NHS chemistry was approximately 3 to $5 \%$ [35]. In our work, the yield exceeded the previous report. We also noticed that without EDC/NHS chemistry there were $2.04 \pm 0.047 \%$ and $1.31 \pm 0.103 \%$ immobilization yields on MC and MCC, respectively.

Table 2. Experimental conditions and resulting immobilization yields. $(n=5)$

\begin{tabular}{ccccc}
\hline Samples & EDC/NHS & $\begin{array}{c}\text { Initial VEGF } \\
\text { concentration } \\
(\mathrm{mg} / \mathrm{mL})\end{array}$ & $\begin{array}{c}\text { Amount of } \\
\text { VEGF } \\
\text { VEGF }(\mathrm{ng})\end{array}$ & $\begin{array}{c}\text { Immobilization yield } \\
(\%)\end{array}$ \\
\hline MC & + & 1 & $47.77 \pm 2.06$ & $4.78 \pm 0.2$ \\
MC & + & 0.5 & $33.78 \pm 1.72$ & $6.76 \pm 0.34$ \\
MCC & + & 1 & $55.38 \pm 5.58$ & $5.54 \pm 0.56$ \\
MCC & + & 0.5 & $40.88 \pm 0.77$ & $8.18 \pm 0.154$ \\
MC & - & 1 & $20.37 \pm 0.47$ & $2.04 \pm 0.047$ \\
MCC & - & 1 & $13.08 \pm 1.03$ & $1.31 \pm 0.103$ \\
\hline
\end{tabular}

\subsection{Adhesion and proliferation of ECs}

The adhesion and spreading abilities of ECs were assessed by seeded ECs on different samples for 30 min. As shown in Figure 5A, more ECs adhered and spread on MAP coating (MC/VEGF and MCC/VEGF) and VEGF covalently immobilized MAP coating (MC/EDC/VEGF and MCC/EDC/VEGF) compared to bare 316 LSS. Almost twice as many ECs were present on the surface coated with MAP compared to bare 316 LSS (Figure 5C). Furthermore, the average spreading area of ECs on MAP coating and VEGF covalently immobilized MAP coating was significantly larger than that on bare 316 LSS, whereas there was no significant difference between different MAP coating (Fig. 5 B and D). 

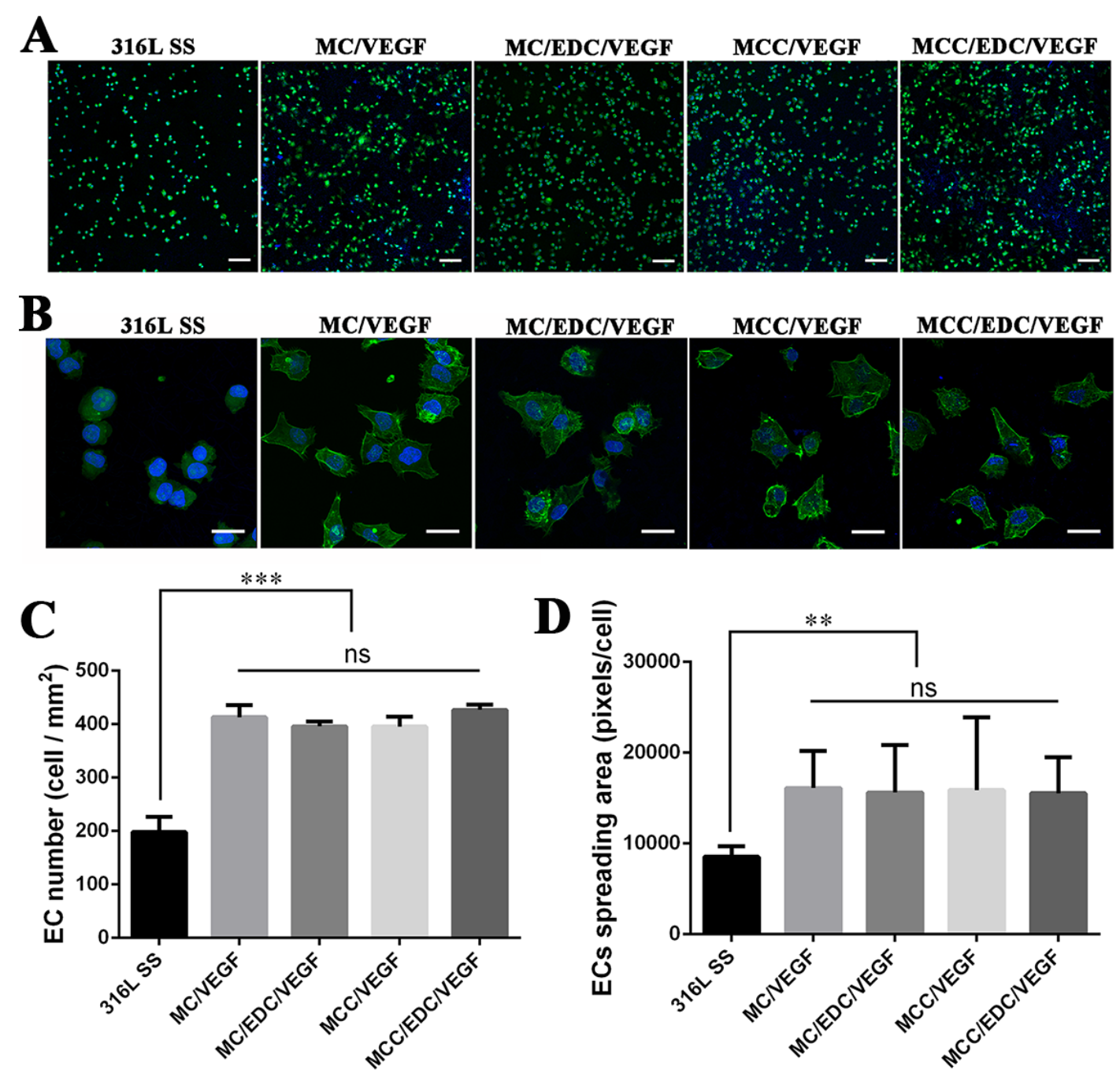

Figure 5. Adhesion and spreading of ECs on various samples. Morphological observations (scale bar $100 \mu \mathrm{m})(\mathrm{A})$, the spreading observations (scale bar $15 \mu \mathrm{m})(\mathrm{B})$, adhesive cells number (C), spreading area (D) of ECs on the various substrates after cell adhesion for $30 \mathrm{~min}$. The initial cell density was $5 \times 10^{4}$ cells per well. Actin filaments were stained with phalloidin-FITC (green), and nuclei were stained with DAPI (blue). The values and error bars represent the means of at least three samples and standard deviations with statistical significance $(* * p<0.01$ and $* * * p<0.001)$. ns, no significance.

To assess the function of the MAP coating containing immobilized VEGF, ECs were seeded on different samples and cultured for 1, 3 and 5 days. The samples were fixed with $2.5 \%$ glutaraldehyde and dehydrated. Finally, the specimens were examined by SEM. As shown in Figure 6A, with covalently immobilized VEGF, the proliferation of ECs was more rapid than without covalently immobilized VEGF. In 
addition, the percentage of spreading area of ECs on MC/EDC/VEGF and MC/EDC/VEGF was significantly higher than others for 3 and 5 days (Fig. 6B). These results suggested that covalently immobilized VEGF on MC and MCC efficiently enhanced ECs' adhesion, spreading and proliferation.

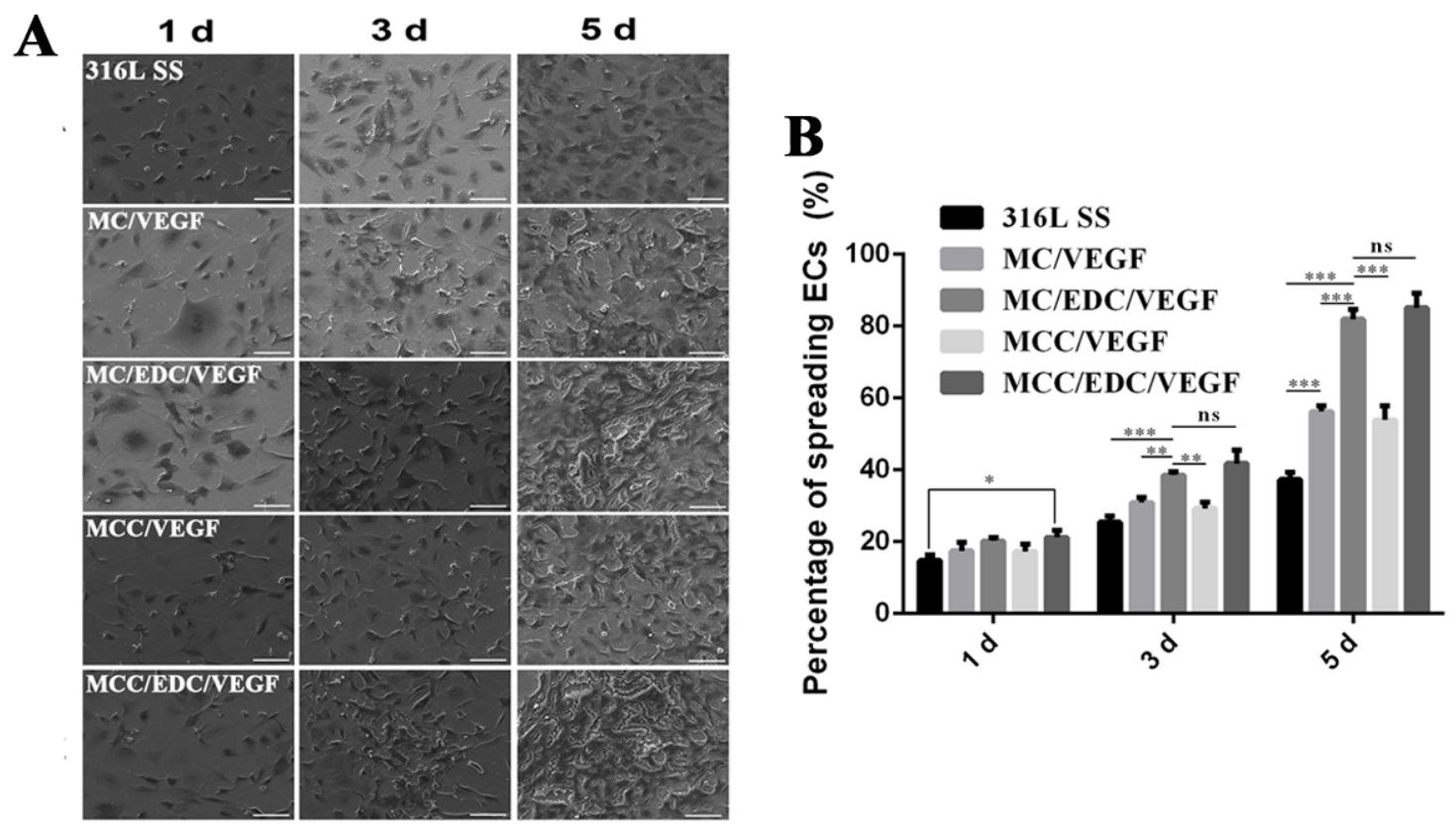

Figure 6. (A)SEM images of ECs cultured on different treatments for 1, 3, 5 days (scale bar $50 \mu \mathrm{m}$ ).

(B) The percentage of spreading area (the spreading areas of all cells/substrates areas) of HUVECs on the various substrates. The values and error bars represent the means of at least three samples and standard deviations with statistical significance $\left({ }^{*} \mathrm{p}<0.05,{ }^{* *} \mathrm{p}<0.01\right.$ and $\left.{ }^{* * *} \mathrm{p}<0.001\right)$. ns, no significance.

\subsection{CD34 antibody coated stents and in Vitro capture tests}

To further investigate the performance of the MAP coating on stents, we prepared CD34 antibody coated stents through MAP coated stents. The fluorescence images of MAP films and PE-labeled CD34 antibody functionalized MAP films are illustrated in Figure 7A. There was a little red fluorescence that can be observed on the MC and MCC without EDC/NHS chemistry. While, in the case of PE-CD34 antibody immobilized on MAP coating with EDC/NHS chemistry, fluorescence tagging of the CD34 antibodies showed uniform distribution on the surface of the stents under fluorescence microscopy, indicating the antibodies have been successfully conjugated to the MAP film. It is also clear that the fluorescence is 
stronger and more uniform on MCC compared with MC under EDC/NHS chemistry. Our results indicate that with EDC/NHS chemistry the amount of immobilized CD34 antibody on MCC was higher than on MC. The films were continuously washed with PBS under mechanical shaking for $24 \mathrm{~h}$ before measurements, with no observed reduction in the mean fluorescence intensity measured, showing antibodies were stably bound (Figure 7B).
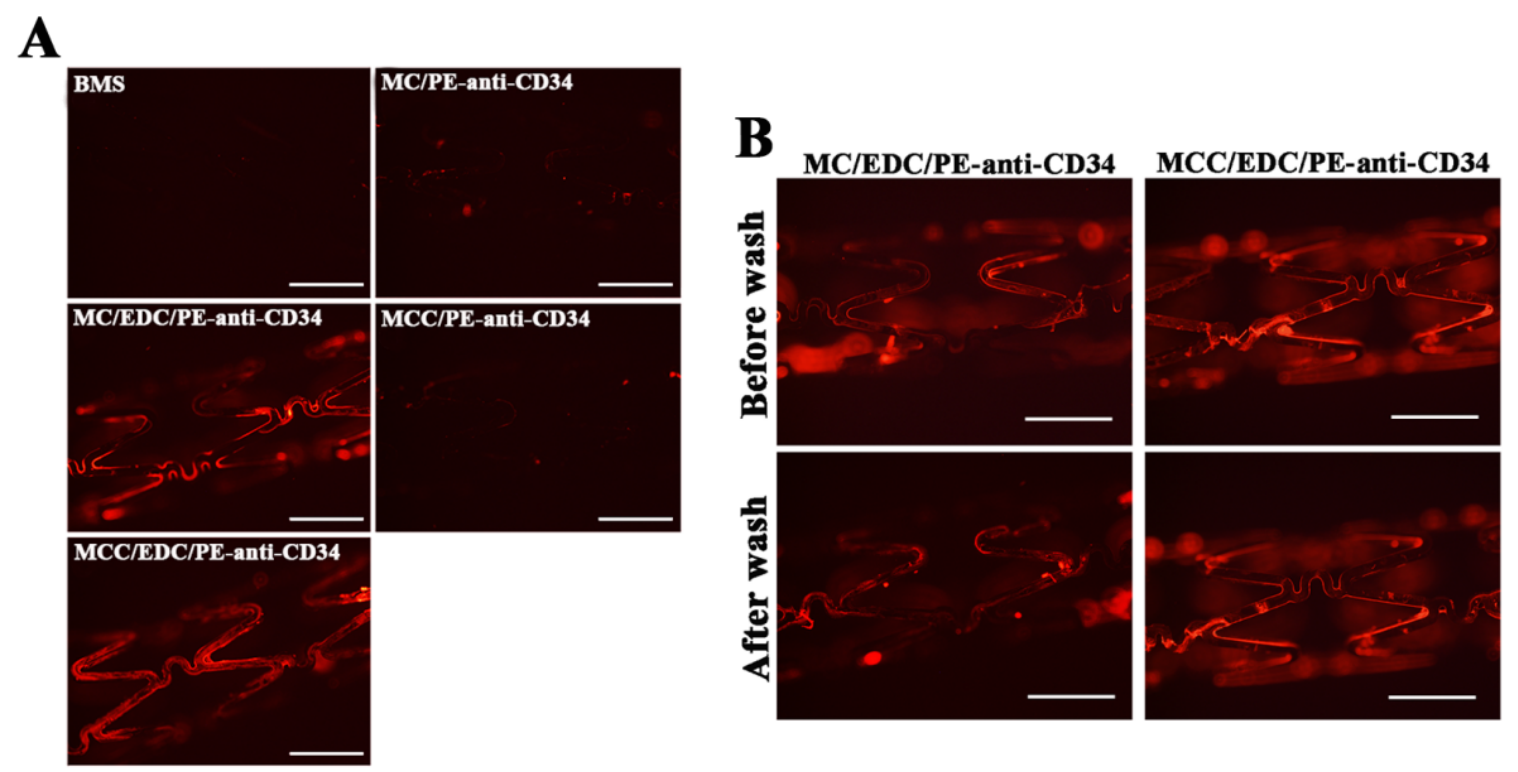

Figure 7. (A) Fluorescence images of BMS and PE-labeled CD34 antibody immobilized on MC or MCC (scale bar 1mm). (B) Fluorescence images of PE-labeled CD34 antibody immobilized on MC and MCC before and after wash (scale bar 1mm).

In vitro KG-1a cells were used to verify the capture ability of the CD34 antibody coated stents. Under fluorescence microscope with DAPI staining, the antibodyimmobilized stents were observed to successfully capture CD34+ $\mathrm{KG}-1$ a cells on the stent surface (Fig. 8A). The MCC/EDC/CD34 antibody coated stents were found to have the highest capture ability. The average rate of absorbance of MCC/EDC/CD34 antibody coated was about $130(n=3)$, which is comparable with a commercial CD34 antibody coated stent (CS) (Fig. 8B). We found that the MC and MCC coatings without EDC/NHS to bind CD34 antibody can also capture the $\mathrm{CD} 34^{+}$cells and the 
capturing amount on MCC is less than on the MC. At the same time, we also found that just the $\mathrm{MC}$ and $\mathrm{MCC}$ can capture a small amount of $\mathrm{CD}^{+} 4^{+}$cells, and the capturing amount on MCC is less than on the MC.

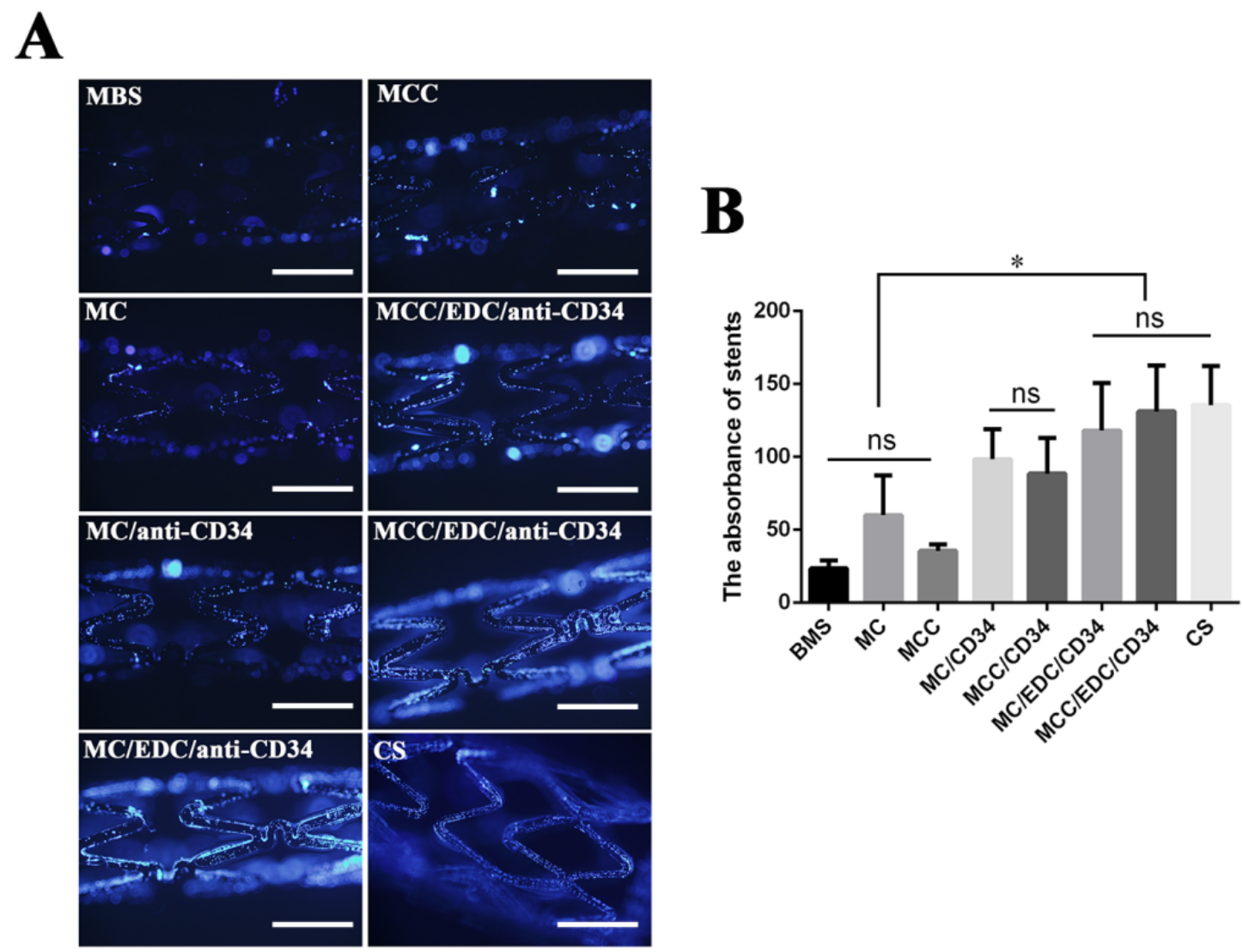

Figure 8. (A) The in vitro $\mathrm{CD} 34^{+}$cell capturing of stents with different treatments. Cells were stained with DAPI (blue). Commercial CD34 antibody stents (CS), (scale bar 1mm ). (B) The absorbance of the different stents after capturing CD34+ cells after dyeing with DAPI. The values and error bars represent the means of at least three samples and standard deviations with statistical significance $(* \mathrm{p}<0.05$,$) . ns, no significance.$

\section{Discussion}

In this study, we reported the development of a surface coating technology through MAP deposition which allows for the covalent immobilization of biomolecules (VEGF or CD34 antibody) onto stent materials. 
Firstly, the relevant properties of the MAP coating were characterized through a series of tests. The MCC has better performance than MC. The surface morphology and roughness were observed with SEM and AFM after MAP coating. The results showed that MAP coating increased the average roughness, while adding glutaraldehyde greatly reduced the average roughness, because glutaraldehyde enhanced the crosslinking degree of MAP when it was deposited on substrates [50, 51]. Ratner et al. [52, 53] hypothesized that, the surfaces of artificial heart valves (AHVs) and cardiovascular stents should be smooth with roughness at the level of protein adsorption $(<50 \mathrm{~nm})$, because otherwise platelets may adhere and thrombogenesis may occur. Obviously, the Ra of the MC and MCC coated 316L SS is low enough for hemocompatibility. Moreover, hemolysis rate of $\mathrm{MC}$ and $\mathrm{MCC}$ were tested in vitro, the results showed that both MC and MCC have a sufficient level of hemocompatibility. In addition, Yun Kee Jo et al. extensively analyzed the blood responses of the MAP coated surface in vitro. MAPs can provide with appropriate surface conditions based on the rapid recruitment of active molecules derived from body fluid and blood cells in a relatively short time after implant insertion. The hemostatic potential of MAP coating can provide better healing by initiating the blood clotting cascade [54]. A water contact angle (WCA) test showed the MAP coating was more hydrophobic compared to the control 316L SS. Moreover, the MCC was more hydrophobic than $\mathrm{MC}$; the reason was that aldehyde groups of glutaraldehyde react with amine groups of lysine and hydroxylysine in MAP [51]. Therefore, the decrease of the content of hydrophilic amine groups in MAP increased the 
hydrophobicity of MCC. Similarly, the cross-linking reaction significantly increased adhesion strength of MCC compared with MC. We also found that the MC and MCC coatings were sufficiently flexible to follow the deformation of the $316 \mathrm{~L}$ SS that allows balloon expansion of the stent without cracking or peeling from the struts. As has been reported in the literature on several occasions, cytotoxicity has proved undesirable side-effect of chemical crosslinking processes [50]. However, through our cell cytotoxicity tests, we found that $\mathrm{MC}$ and $\mathrm{MCC}$ both have good cytocompatibility. Taken together, our results demonstrate that MAP can be coated on metal stent materials through our methods. Previous study reported that at mid to higher $\mathrm{pH}$ levels the Dopa residues in MAP may oxidized into dopaquinones to enhance protein cross-linking [23] and the Dopa can also interact with metal ions to form metalcatecholate complexes [57]. So, MAP can rapidly absorb on substrates to form a coating. Additionally, through adding the glutaraldehyde, the MCC was found to possess lower roughness, higher hydrophobicity and stronger adhesion than MC. Meanwhile, MC and MCC were both found to exhibit good biocompatibility.

In order to stimulate the positive reaction of endothelial cells upon injury to the vessel wall and stent deployment, many efforts to accelerate the surface endothelialization of the stent has been attempted with positive results. For instance, bioactive proteins and polypeptides have been applied to the surface to enhance the attachment, viability, proliferation and retention of cells [55]. In our work, VEGF was further immobilized on MAP coating by EDC/NHS chemistry to create biofunctional coatings. To assess the binding ability of the VEGF, ELISA was used to assess the 
amounts of captured VEGF bound on the MAP coatings ELISA is a common method to characterize biomolecule immobilization [56]. The results indicated that, through EDC/NHS chemistry, VEGF was successfully covalently bound on MC and MCC. Under the same conditions, the amount and the bound yield on MCC are higher than MC, although there were no significant differences between MCC and MC. Without EDC/NHS chemistry, VEGF also was immobilized on MC and MCC. The reason may be that the MAP contains some lysine residues [57], through electrostatic interaction MC and MCC can bind some VEGF. However, after cross-linking reaction with glutaraldehyde, on MCC some lysines was reacted, which have lower electrostatic interaction with VEGF. We also found that using a lower concentration of VEGF results in higher immobilization yields when utilized with EDC/NHS chemistry. The results were consistent with a previous report, although the reason for this finding remains unclear [41]. Although it is difficult to compare our results with others, mainly due to this being the first study which uses MAP as a coating to immobilize macromolecules, it should be noted that secondary ligation of VEGF via the deposited MAP layer was very effective under our experimental conditions. Our results clearly indicated that with EDC/NHS chemistry VEGF was successfully immobilized on the MC and MCC in a concentration-dependent manner and the imbililization ability on MCC was higher than MC.

The characterization of bioactive surfaces involving grafted biomolecules is important to understand their biological outcomes. To detect the bioactivity of VEGF which immobilized on MAP coating, HUVECs were seeded on different samples in 
vitro. Our results show that that the creation of a bifunctional coating by binding VEGF on a MAP coating can improves the adhesion, spreading and proliferation of ECs.

Many previous studies reported that EPCs may be captured by immobilizing CD34 antibodies on stent surfaces by covalently binding to polymer carriers [58-60]. In our work, to further investigate the performance of MAP coating to bind biomolecules, CD34 antibody also was bound on MC and MCC by the same method as VEGF binding. Through PE-labeled CD34 antibody, we found that using the same method, the antibodies have been successfully conjugated to the MAP film and the binding amount of CD34 antibody on MCC are also higher than MC. We also found that the MC and MCC can bind with a certain amount of CD34 antibody without EDC/NHS chemistry (albeit, capturing only a few of the $\mathrm{CD}^{+} 4^{+}$cells). The results were consistent with previous VEGF bond on MC and MCC. In vitro capture tests showed that CD34 antibody coated stents in which CD34 antibody was bound on the MCC can capture $\mathrm{CD}^{+} 4^{+}$cells at a level comparable with a commercial CD34 antibody coated stent. Interestingly, just the MC and MCC also could capture a small amount of $\mathrm{CD}^{+} 4^{+}$cells, with the capturing amount on MCC less than the MC. This reason was that MAP contains some lysine residues [57]. After coating on stent materials, the MAP coating shows some positive charges, and normally the cell membrane shows negative charge. Therefore, a few cells can have adhered on MC and MCC, through the electrostatic interaction. Owing to using glutaraldehyde as crossing agent on MCC, some amine groups reacted with glutaraldehyde [51]. So, there were less cells adhered 
on MCC than MC.

Collectively, these results suggest that MAP could be coated on stent materials through simple dip-coating of objects in an aqueous solution of MAP. MC and MCC are sufficiently flexible to follow the deformation of vascular stents during balloon expansion without cracking or peeling from the struts. Moreover, MCC have higher coating performance than MC. It is important that MC and MCC have good blood compatibility and cytocompatibility. The coating can further covalently bond biomolecules (VEGF, CD34 antibody) using EDC/NHS chemistry and MCC have higher binding efficiency. Importantly, the bound VEGF and CD34 antibodies on the MAP coating retained their bioactivity. However, we recognize that further work is required to demonstrate true biocompatibility of this surface. In particular, the effect of this new surface on platelet adhesion, thrombogenicity and inflammation warrant further investigation [61].

\section{Conclusions}

The data in this study show that MAP can be deposited onto 316L stainless steel (SS) stents. We demonstrated that MAP used as a stent coating shows good resistance to the deformation behavior of compression and expansion of a stent. Moreover, MCC have more favorable coating properties than MC. The MC and MCC coatings both have good biocompatibility. Using EDC/NHS chemistry, we successfully immobilized VEGF or CD34 antibody on MC and MCC coated medical 316L Stainless Steel substrates and stents. The immobilization efficiency on MCC was higher than MC under the same conditions. In vitro, the immobilized VEGF enhanced 
HUVECs proliferation and viability and the CD34 antibody coated stents have the ability to capture $\mathrm{CD} 4^{+}$cells, suggesting that they maintained biological activity after immobilization setup. In conclusion, we have developed a new method to form multifunctional coatings through simple dip-coating of objects in solution of MAP. In addition, the combination of MAP and biomolecule coating provides a potential strategy for controlling cell behavior on the surfaces of vascular implant materials.

\section{Acknowledgements}

This research program was supported by grants from the National Natural Science Foundation of China $(11332003,11572064)$, the National Key Research and Development Program of China (2016YFC1102305), the Fundamental Research Funds for the Central Universities (106112017CDJZRPY0012, 106112017CDJQJ238814, 106112017CDJZRPY0021) as well as the Public Experiment Center of State Bioindustrial Base (Chongqing), China.

\section{Disclosures}

The authors declare no conflicts of interest.

\section{References}

[1] H. Takahashi, D. Letourneur, D.W. Grainger, Biomacromolecules, 8 (2007) 3281-3293.

[2]Y.B. Wang, X.D. Zhang, Regen Biomater, 1 (2014) 49-55

[3] T.Z. Hu, J.L. Yang, K. Cui, Q. Rao, T.Y. Yin, L.L. Tan, Y. Zhang, Z.G. Li, G.X. Wang, ACS Applied Materials \& Interfaces, 7 (2015) 11695-11712.

[4] P. McHugh, A. Barakat, S. McGinty, Ann Biomed Eng, 44 (2016) 274-275.

[5] R.A. Byrne, P.W. Serruys, A. Baumbach, J. Escaned, J. Fajadet, S. James, M. Joner, S. Oktay, P. Juni, A. Kastrati, G. Sianos, G.G. Stefanini, W. Wijns, S. Windecker, Eur Heart J, 36 (2015) 26082620.

[6] J. Hong, A. Azens, K.N. Ekdahl, C.G. Granqvist, B. Nilsson, Biomaterials, 26 (2005) 1397-1403.

[7] G. Mani, M.D. Feldman, D. Patel, C.M. Agrawal, Biomaterials, 28 (2007) 1689-1710.

[8] R. Singh, N.B. Dahotre, J Mater Sci-Mater M, 18 (2007) 725-751. 
[9] R. Hao, R.J. Xing, Z.C. Xu, Y.L. Hou, S. Gao, S.H. Sun, Advanced materials, 22 (2010) 2729-2742. [10] J.P. Chen, C.H. Su, Acta Biomaterialia, 7 (2011) 234-243.

[11] Z.Y. Qiu, C. Chen, X.M. Wang, I.S. Lee, Regen Biomater, 1 (2014) 67-79

[12] D.K. Knight, R. Stutchbury, D. Imruck, C. Halfpap, S.G. Lin, U. Langbein, E.R. Gillies, S. Mittler, K. Mequanint, ACS Applied Materials \&Interfaces, 4 (2012) 1303-1312.

[13] D. Dechtrirat, N. Gajovic-Eichelmann, F.F. Bier, F.W. Scheller, Advanced Functional Materials, 24 (2014) 2233-2239.

[14] A. Singh, M. Corvelli, S.A. Unterman, K.A. Wepasnick, P. McDonnell, J.H. Elisseeff, Nature Materials, 13 (2014) 988-995.

[15] G. Li, P. Yang, W. Qin, M.F. Maitz, S. Zhou, N. Huang, Biomaterials. 32 (2011) 4691-703.

[16] P. Qi, M.F. Maitz, N. Huang, Surface \& Coatings Technology, 233 (2013) 80-90.

[17] Z.L. Yang, J. Wang, R.F. Luo, M.F. Maitz, F.J. Jing, H. Sun, N. Huang, Biomaterials 31 (2010) 2072-2083.

[18] J.H. Waite, M.L. Tanzer, Science, 212 (1981) 1038-1040.

[19] J.H. Waite, International Journal of Adhesion and Adhesives, 7 (1987) 9-14.

[20] L.M. Rzepecki, K.M. Hansen, J.H. Waite, Biol Bull, 183 (1992) 123-137.

[21] V.V. Papov, T.V. Diamond, K. Biemann, J.H. Waite, J Biol Chem, 270 (1995) 20183-20192.

[22] J.H. Waite, X.X. Qin, Biochemistry-Us, 40 (2001) 2887-2893.

[23] L.A. Burzio, J.H. Waite, Biochemistry-Us, 39 (2000) 11147-11153.

[24] M.J. Sever, J.T. Weisser, J. Monahan, S. Srinivasan, J.J. Wilker, Angew Chem Int Edit, 43 (2004) 448-450.

[25] H. Lee, N.F. Scherer, P.B. Messersmith, Proceedings of the National Academy of Sciences of the United States of America, 103 (2006) 12999-13003.

[26] H.G. Silverman, F.F. Roberto, Mar Biotechnol, 9 (2007) 661- 681.

[27] D.C. Yang, J.H. Qiu, N. Xu, Y.P. Zhao, T.H. Li, Q.F. Ma, J.L. Huang, G.X. Wang, J. Mater. Chem. B, 6 (2018) 4151-4163.

[28] D.S. Hwang, Y. Gim, D.G. Kang, Y.K. Kim, H.J. Cha, J Biotechnol, 127 (2007) 727-735.

[29] D.S. Hwang, Y. Gim, H.J. Yoo, H.J. Cha, Biomaterials, 28 (2007) 3560-3568.

[30] D.S. Hwang, S.B. Sim, H.J. Cha, Biomaterials, 28 (2007) 4039-4046.

[31] H.J. Cha, D.S. Hwang, S. Lim, Biotechnology Journal, 3 (2008) 631-638.

[32] D.A. Grande, M.I. Pitman, B Hosp Joint Dis Ort, 48 (1988) 140-148.

[33] M.I. Pitman, D. Menche, E.K. Song, A. Benyishay, D. Gilbert, D.A. Grande, B Hosp Joint Dis Ort, 49 (1989) 213-220.

[34] J.P. Fulkerson, L.A. Norton, G. Gronowicz, P. Picciano, J.M. Massicotte, C.W. Nissen, J Orthopaed Res, 8 (1990) 793-798.

[35] K.S. Masters, Macromol Biosci, 11 (2011) 1149-1163.

[36] G. Ahrendt, D.E. Chickering, J.P. Ranieri, Tissue Eng, 4 (1998) 117-130.

[37] T. Boontheekul, D.J. Mooney, Current Opinion in Biotechnology, 14 (2003) 559-565.

[38] X. Wu, Y.P. Zhao, C.J. Tang, T.Y. Yin, R.L. Du, J. Tian, J.L. Huang, H. Gregersen, G.X. Wang, ACS Applied Materials \& Interfaces, 8 (2016) 7578-7589.

[39] W.L. Murphy, M.C. Peters, D.H. Kohn, D.J. Mooney, Biomaterials, 21 (2000) 2521-2527.

[40] C.K. Poh, Z.L. Shi, T.Y. Lim, K.G. Neoh, W. Wang, Biomaterials, 31 (2010) 1578-1585.

[41] A.G. Guex, D. Hegemann, M.N. Giraud, H.T. Tevaearai, A.M. Popa, R.M. Rossi, G. Fortunato, Colloid Surface B, 123 (2014) 724-733. 
[42] P. Lequoy, F. Murschel, B. Liberelle, S. Lerouge, G. De Crescenzo, Acta Biomaterialia, 29 (2016) 239-247.

[43] T. Asahara, T. Murohara, A. Sullivan, M. Silver, R. vanderZee, T. Li, B. Witzenbichler, G. Schatteman, J.M. Isner, Science, 275 (1997) 964-967.

[44] X. Wu, T.Y. Yin, J. Tian, C.J. Tang, J.L. Huang, Y.P. Zhao, X.J. Zhang, X.Y. Deng, Y.B. Fan, D. H. Yu and G.X. Wang, Regen Biomater, 2 (2015) 87-96.

[45] F. Chen, F. Yang, Q. Zhao, S.C. Feng, W.X. Li, Y.H. Bi, S.X. Zhang, Y. Wang, B. Feng, J Interv Cardiol, 28 (2015) 257-263.

[46] H.L. Lan, Y. Wang, T.Y. Yin, Y.Z. Wang, W.Q. Liu, X.J. Zhang, Q.S. Yu, Z.X. Wang, G.X. Wang, J Biomed Mater Res B, 104 (2016) 1237-1247.

[47] L.L.Y. Chiu, R.D. Weisel, R.K. Li, M. Radisic, J Tissue Eng Regen M, 5 (2011) 69-84.

[48] M. Sasaki, M. Inoue, Y. Katada, T. Taguchi, Colloid Surface B, 92 (2012) 1-8.

[49] L.H. Li, M. Tu, S.S. Mou, C.G. Zhou, Biomaterials, 22 (2001) 2595-2599.

[50] M.G. Haugh, C.M. Murphy, R.C. McKiernan, C. Altenbuchner, F.J. O'Brien, Tissue Eng Pt A, 17 (2011) 1201-1208.

[51] S. Gao, Z.G. Yuan, W.M. Guo, M.X. Chen, S.Y. Liu, T.F. Xi, Q.Y. Guo, Mat Sci Eng C-Mater, 71 (2017) 891-900.

[52] B.D. Ratner, Nato Adv Sci I E-App, 346 (1997) 453-464.

[53] B.D. Rattier, A.S. Hoffman, F.J. Schoen, J.E. Lemons, Journal of Clinical Engineering, 22 (1997) 26.

[54] Y.K. Jo, B.H. Choi, C. Zhou, J.S. Ahn, S.H. Jun, H.J. Cha, J. Mater. Chem. B, 3 (2015) 8102-8114.

[55] C.Y. Wang, Y. Liu, Y.B. Fan, X.M. Li, Regen Biomater, 4 (2017) 191-206.

[56] L.L.Y. Chiu, M. Radisic, Biomaterials, 31 (2010) 226-241.

[57] N. Holten-Andersen, J.H. Waite, Journal of Dental Research, 87 (2008) 701-709.

[58] J. Aoki, A.T.L. Ong, E.P. McFaden, W.J. van der Giessen, G. Sianos, E. Regar, P. de Feyter, M.J.B. Kutryk, P.W. Serruys, J Am Coll Cardiol, 45 (2005) 69a-69a.

[59] Q.K. Lin, X. Ding, F.Y. Qiu, X.X. Song, G.S. Fu, J. Ji, Biomaterials, 31 (2010) 4017-4025.

[60] G. Nakazawa, J.F. Granada, C.L. Alviar, A. Tellez, G.L. Kaluza, M.Y. Guilhermier, S. Parker, S.M. Rowland, F.D. Kolodgie, M.B. Leon, R. Virmani, JACC-Cardiovasc Inte, 3 (2010) 68-75.

[61] M.B. Gorbet, M.V. Sefton, Biomaterials, 25 (2004) 5681-5703. 